\title{
Effects of $\alpha$-ZrP on Crystallinity and Flame-Retardant Behaviors of PA6/MCA Composites
}

\author{
Yuanfang Xiao, Jiayou Xu, Siwen Huang, and Haiming Deng \\ Department of Chemistry \& Chemical Engineering, Guangzhou University, Guangzhou 510006, China \\ Correspondence should be addressed to Jiayou Xu; xujiayou516@sohu.com
}

Received 15 October 2016; Accepted 1 December 2016; Published 3 January 2017

Academic Editor: De-Yi Wang

Copyright (c) 2017 Yuanfang Xiao et al. This is an open access article distributed under the Creative Commons Attribution License, which permits unrestricted use, distribution, and reproduction in any medium, provided the original work is properly cited.

\begin{abstract}
Novel flame-retardant Polyamide6/Melamine cyanurate-alpha-zirconium phosphate (PA6/MCA- $\alpha$-ZrP) composites were prepared via the incorporation of the modified MCA (MCA- $\alpha$-ZrP) into PA6. MCA- $\alpha$-ZrP were synthesized through the self-assembly of $\alpha$-ZrP, Melamine (ME), and cyanuric acid (CA) molecules. The results of differential scanning calorimetry (DSC) and X-ray diffraction (XRD) showed that the incorporation of enough $\alpha$-ZrP (30 wt\% MCA) caused the increased crystallinity of PA6 and tended to form $\gamma$ phase. The thermogravimetric analysis (TGA) and heat distortion temperature (HDT) test illustrated that the $\alpha$ $\mathrm{ZrP}$ could increase the residue and HDT values of PA6/MCA and showed a synergistic effect with MCA. The combination of MCA and $\alpha-\mathrm{ZrP}$ caused the enhancement of vertical burning test (UL-94) rating. Cone calorimeter test (CCT) gave clear evidences that PA6/MCA-10 $\alpha$-ZrP composites with low heat release rate (HRR), low total heat release (THR), and high amounts of char residues after combustion compared with PA6/MCA and PA6/MCA-30 $\alpha$-ZrP. What is more, excellent mechanical properties were kept even though MCA and $\alpha$-ZrP were dispersed not as good as expected.
\end{abstract}

\section{Introduction}

PA6 is widely used in industry and daily life, which is due to its excellent mechanical, electrical, abrasion resistant, oil resistant, solvent resistant, and corrosion resistant properties [1-4]. However, the natural flammability and low fire-resistance of PA6 limit its wide applications. Melamine cyanurate (MCA), as a traditional flame retardant, is usually used in PA6, which is halogen-free and can significantly improve the fire retardancy of PA6. However, high loading of MCA in PA6 results in processing difficulties and mechanical properties deterioration to achieve identical flame retardancy.

In recent years, increasing and considerable attention have been drawn in layered nanofillers (like montmorillonite) to improve the flame-retardant properties of polymers [5-8]. Alpha-zirconium phosphate $(\alpha-\mathrm{ZrP})$ possesses some unique advantages over other layered nanofillers, such as highly tunable properties and ease of intercalation [9-15]. Moreover, many reports indicate that $\alpha-\mathrm{ZrP}$ are also able to catalyze carbonization and graphitization on the surface of polymer composites [16-21]. So, in our work, $\alpha-\mathrm{ZrP}$ is used as synergistic agent of MCA to create novel flame-retardant system which may further improve the flame-retardant and mechanical properties.

$\alpha$-ZrP modified MCA (MCA- $\alpha-\mathrm{ZrP}$ ) were synthesized through the self-assembly between $\alpha$-ZrP, Melamine (ME), and cyanuric acid (CA) molecules, and the structure of MCA and MCA- $\alpha-\mathrm{ZrP}$ was characterized. A certain amount of MCA or MCA- $\alpha-\mathrm{ZrP}$ was incorporated into PA6 by melt blending to obtain a series of PA6/MCA and PA6/MCA- $\alpha$ $\mathrm{ZrP}$ composites, and the flame retardancy, mechanical properties, thermal stability, and crystallinity of each composite were investigated.

\section{Experimental}

2.1. Materials. Alpha-zirconium phosphate $(\alpha-\mathrm{ZrP})$ was purchased from Xiya Reagent Co., Ltd. (Chengdu, China). Melamine (ME) and cyanuric acid (CA) were provided by Sinopharm Chemical Reagent Co., Ltd. (Shanghai, China). Polyamide6 (PA6) was supplied by Meijuke company (Foshan, China). 
TABLE 1: Formulation and TGA data of the pure PA6 and its composites.

\begin{tabular}{lcccccc}
\hline Samples ID & Composites & MCA- $\alpha-\operatorname{ZrP}(\alpha-\mathrm{ZrP})(\mathrm{wt} \%)$ & $T_{\max 1}\left({ }^{\circ} \mathrm{C}\right)$ & $T_{i}\left({ }^{\circ} \mathrm{C}\right)$ & $T_{\max 2}\left({ }^{\circ} \mathrm{C}\right)$ & Residue char $(\%)$ \\
\hline 1 & PA6 & 0 & - & 362 & 457 & 0 \\
2 & PA6/MCA & $12(0)$ & 340 & 386 & 454 & 0 \\
3 & PA6/MCA-3 $\alpha-Z r P$ & $12(0.36)$ & $12(0.60)$ & 342 & 382 & 457 \\
4 & PA6/MCA-5 $\alpha-Z r P$ & $12(1.20)$ & 343 & 382 & 442 & 0 \\
5 & PA6/MCA-10 $\alpha-Z r P$ & $12(3.60)$ & 342 & 383 & 440 & 1.38 \\
6 & PA6/MCA-30 $\alpha-Z r P$ & & 380 & 438 & 3.12 \\
\hline
\end{tabular}

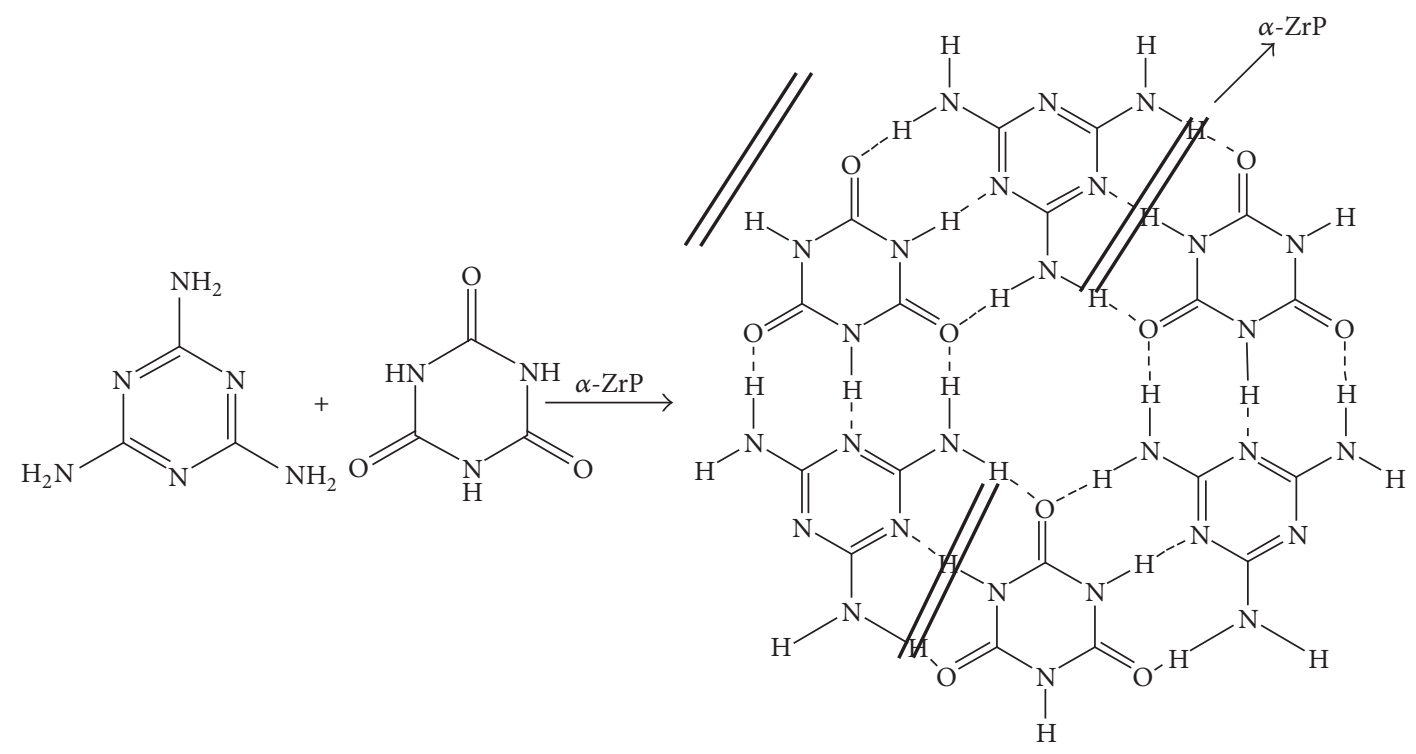

Scheme 1: Schematic figures of the reaction between ME, CA, and $\alpha-\operatorname{ZrP}$.

2.2. Synthesis of MCA and MCA- $\alpha-Z r P$. CA and water were added to a three-necked flask with stirring to obtain the stable suspension. Then, $\alpha$ - $\mathrm{ZrP}$ was poured into the stirring suspension. Besides, ME was not put into flask until the mixture temperature was up to $80^{\circ} \mathrm{C}$. The mixture was stirred at $95^{\circ} \mathrm{C}$ for $2 \mathrm{~h}$. The resulting MCA was dried at $120^{\circ} \mathrm{C}$ for $12 \mathrm{~h}$. At last, MCA- $\alpha-\mathrm{ZrP}$ ( $\alpha-\mathrm{ZrP}$ account for $3 \%, 5 \%, 10 \%$, and $30 \% \mathrm{MCA}$, resp.) were acquired with pestle. The reaction scheme for MCA- $\alpha$-ZrP was shown in Scheme 1.

2.3. Preparation of Flame-Retardant PA6 Composites. The content of flame-retardant (MCA or MCA- $\alpha-\mathrm{ZrP}$ ) in PA6 composites was kept at $12 \mathrm{wt} \%$. PA6, MCA, and MCA- $\alpha-\mathrm{ZrP}$ were dried at $80^{\circ} \mathrm{C}$ for $12 \mathrm{~h}$ before use. The formulation of PA6 composites was listed in Table 1 . All the composites were blended by a twin screw extruder. The resulting samples were pelletized and then melted and injected into the standard models to prepare specimens according to corresponding test standards.

2.4. Characterization. Fourier transform infrared (FTIR) spectra were carried out using a Nicolet IS-10 spectrometer. Potassium bromide pellet was used as background. The wavenumber range was set from 4000 to $400 \mathrm{~cm}^{-1}$.
X-ray diffraction (XRD) patterns were recorded with X'Pert PRO MPD X-ray diffractometer with a $\mathrm{Cu}-\mathrm{K} \alpha$ generator $(\lambda=0.154 \mathrm{~nm})$ in the range of $5^{\circ}$ to $90^{\circ}$ with a scanning rate of $0.06^{\circ}$ s.

Thermogravimetric analysis (TGA) tests were performed in air atmosphere on a PerkinElmer TGA 2050 instrument at a heating rate of $10^{\circ} \mathrm{C} / \mathrm{min}$ at temperature ranging from 30 to $700^{\circ} \mathrm{C}$.

Differential scanning calorimetry (DSC) measurements were interfaced with a TA 2010 (TA instruments) under $\mathrm{N}_{2}$ atmosphere in a heating rate $10^{\circ} \mathrm{C} / \mathrm{min}$ at temperature ranging from 30 to $300^{\circ} \mathrm{C}$. The thermograms were recorded with first heating and then cooled to $20^{\circ} \mathrm{C}$.

Scanning electronic microscopy (SEM) images were observed on a JEOL JSM-6380LV SEM. The samples were recorded after gold coating surface treatment.

Transmission electron microscopy (TEM) were investigated on a JEOL JEM-2100 with a $200 \mathrm{kv}$ accelerating voltage.

Tensile properties were conducted on an Instron universal testing machine according to ASTM B638-99 with testing speed $50 \mathrm{~mm} / \mathrm{min}$. V-notch impact tests were measured by using a Pendulum impact testing machine (ZBC-1251-12) in accordance with ASTMD638-99.

Heat distortion temperature (HDT) were carried out on a HDT 3VICAT in accordance with ASTM D 648 with surface stress $1.82 \mathrm{Mpa}$ and heating rate $120^{\circ} \mathrm{C} / \mathrm{h}$. 


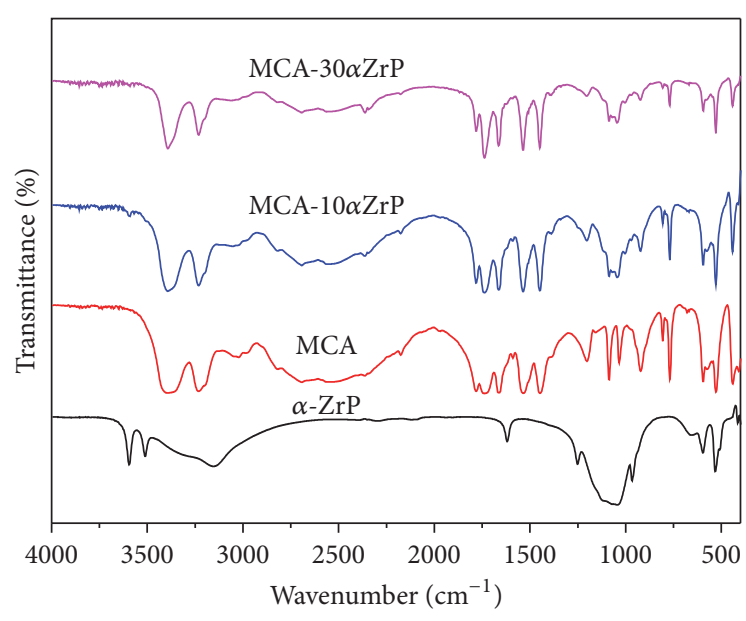

FIGURE 1: FTIR spectra of $\alpha$-ZrP, MCA, and MCA- $\alpha$-ZrP. Each curve in the FTIR data is shifted vertically.

Fire behavior were characterized by UL-94 test (ASTM D635-77) and Cone calorimeter test (CCT). UL-94 tests were performed on a CZF-2 vertical burning test instrument with sheet dimensions of $127 \times 12.7 \times 3.2 \mathrm{~mm}^{3}$. CCT were tested by using a Fire Testing Technology cone calorimeter on $100 \times$ $100 \times 3.2 \mathrm{~mm}^{3}$ according to ISO $5660-1$ with an external heat flux of $50 \mathrm{~kW} / \mathrm{m}^{2}$. All the data presented in the following were reproducible within $\pm 5 \%$ and were average based on three measurements.

\section{Results and Discussion}

3.1. Characterization of MCA- $\alpha-Z r P$. To illustrate whether there are chemical reactions between MCA and $\alpha$-ZrP or not, direct evidence can be obtained from FTIR as shown in Figure 1. It is evident that the scissoring bands assigned at $3385 \mathrm{~cm}^{-1}, 3194 \mathrm{~cm}^{-1}, 1785 \mathrm{~cm}^{-1}, 1715 \mathrm{~cm}^{-1}, 1665 \mathrm{~cm}^{-1}$, and $1419 \mathrm{~cm}^{-1}$ are ascribed to MCA characteristic absorption peaks of $\mathrm{N}-\mathrm{H}, \mathrm{C}-\mathrm{H}, \mathrm{C}=\mathrm{O}, \mathrm{C}=\mathrm{O}, \mathrm{C}=\mathrm{N}$, and $\mathrm{C}-\mathrm{N}$, respectively. MCA-10 $\alpha-Z r P$ and MCA- $30 \alpha-Z r P$ showed no apparent differences compared with MCA, indicating that there are no new substances appearing in this reaction or the MCA peaks are too intensive to show $\alpha$-ZrP peaks.

For further identification, the chemical structures of MCA and MCA- $\alpha-\mathrm{ZrP}$ were investigated by XR, as shown in Figure 2. The XRD pattern for MCA exhibited diffraction peaks at $2 \theta$ of $11.03^{\circ}, 11.96^{\circ}, 21.95^{\circ}, 28.05^{\circ}$, and $33.18^{\circ}$. There are also no obvious differences between MCA and MCA- $\alpha-\mathrm{ZrP}$, deeply demonstrating that there are no chemical reactions between MCA and $\alpha$-ZrP, which is in accord with FTIR results.

The SEM images of MCA, MCA- $30 \alpha-\mathrm{ZrP}$, and $\alpha-\mathrm{ZrP}$ are shown in Figure 3. Many researchers reported that the synthesis of MCA was planar molecules self-assembly of ME and CA by forming a large flat hydrogen bond network [22-25]. $\alpha-\mathrm{ZrP}$ can break the hydrogen bond network into much smaller independent reaction systems and the MCA particles were refined. Figure 3(a) showed that MCA particles

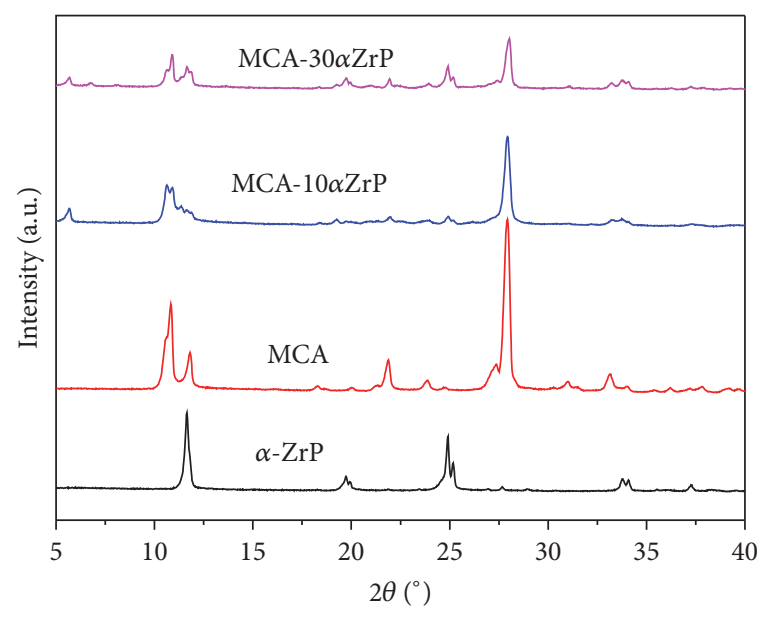

FIGURE 2: XRD patterns of MCA and MCA- $\alpha$-ZrP. For clarity, the curves have been arbitrarily shifted vertically.

present different sizes and irregular shapes. From Figures $3(\mathrm{~b})$ and 3(c), it can be seen that MCA particles become smaller compared with MCA when $\alpha$ - ZrP was added to this system, and some capsule-shaped particles existed, which can be explained by coated $\alpha-\mathrm{ZrP}$ with MCA.

3.2. Dispersibility of Flame Retarded PA6 Composites. The morphology of MCA and MCA- $\alpha$-ZrP dispersed in PA6 was investigated via SEM. The SEM images of fracture surface are shown in Figure 4. The image of pure PA6 only exhibits some flaws in the surface. The image of PA6/MCA revealed that a large number of irregular MCA particles with sphere-like, rod-like, and flake-like shapes were unevenly dispersed in the PA6 matrix. With $\alpha$-ZrP added to PA6/MCA system, layered structure of $\alpha$-ZrP and MCA particles would be seen and also unevenly distributed in PA6/MCA-10 $\alpha-\mathrm{ZrP}$ and PA6/MCA$30 \alpha$-ZrP.

Further evidence is seen by TEM as shown in Figure 5. Figures 5(a) and 5(b) show PA6/MCA internal structures on nanometre scale, the arrowed dark entitles can be clearly observed and also be not homogenously distributed. From Figures 5(c) and 5(d), layered $\alpha$-ZrP (circled) and irregular MCA (arrowed) particles exist on the images and also heterogeneously dispersed in PA6. From these results, it can be concluded that MCA and $\alpha$-ZrP were dispersed in PA6 matrix not as good as expected.

3.3. Thermal Stability of Flame Retarded PA6 Composites. In order to understand the effect of MCA- $\alpha$-ZrP on the thermal stability of PA6, the pure PA6 and the flame-retardant PA6 systems with various amounts of $\alpha$-ZrP modified MCA were analyzed by TGA. The TG and DTG curves of pure PA6, PA6/MCA, and PA6/MCA- $\alpha-Z r P$ were shown in Figure 6. And their data were listed in Table 1 . The thermal stability was quantified through the initial decomposition temperature $\left(T_{i}\right)$ and the maximum degradation temperatures $\left(T_{\max 1}\right.$ and $\left.T_{\max 2}\right)$. The TG curve of PA6 had one stage of thermal degradation. $T_{i}$ of pure PA6 was $362^{\circ} \mathrm{C}$ and $T_{\max }$ was $457^{\circ} \mathrm{C}$. 

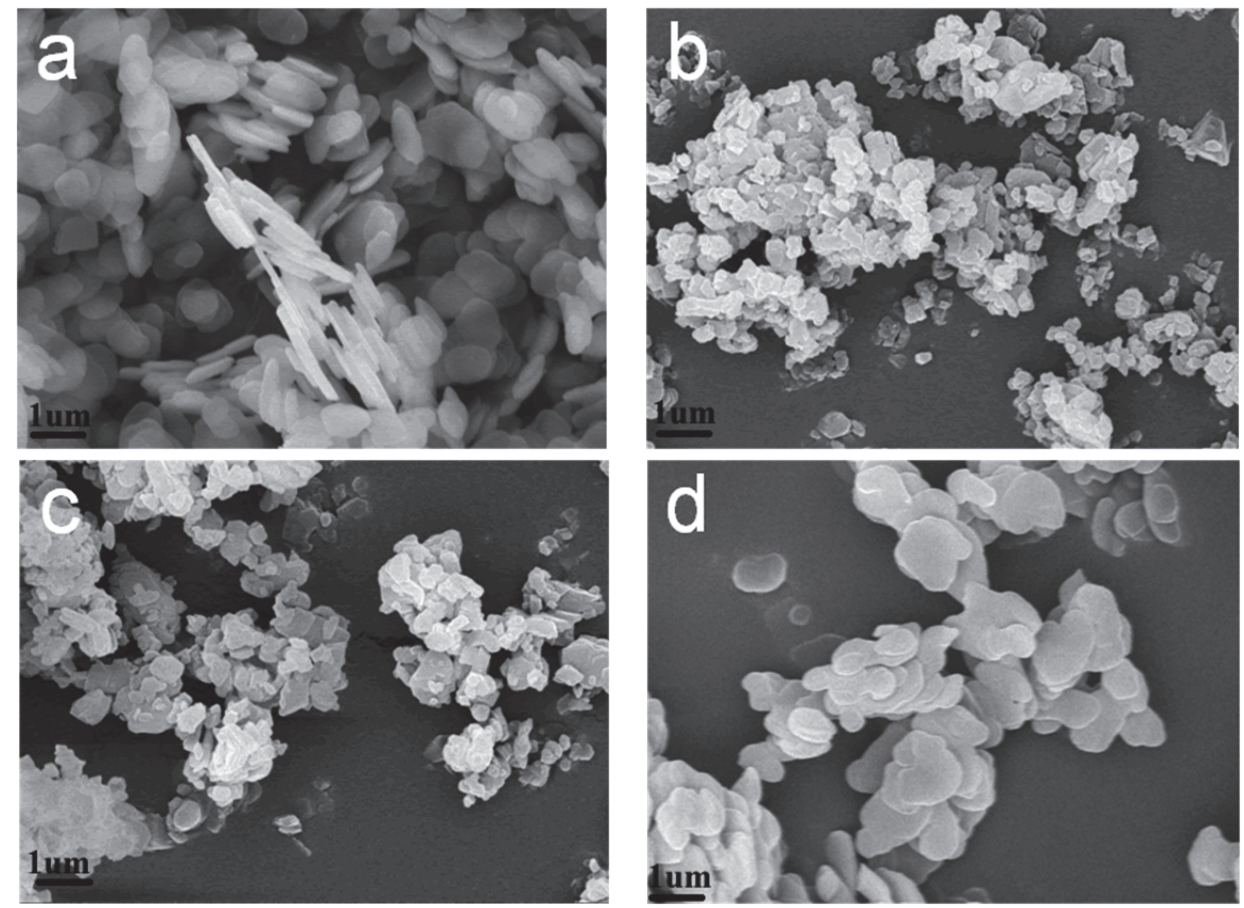

Figure 3: SEM images of MCA and MCA- $\alpha-\mathrm{ZrP}$ : (a) MCA, (b) MCA-10 $\alpha-Z r P$, (c) MCA-30 $\alpha-Z r P$, and (d) $\alpha-Z r P$.
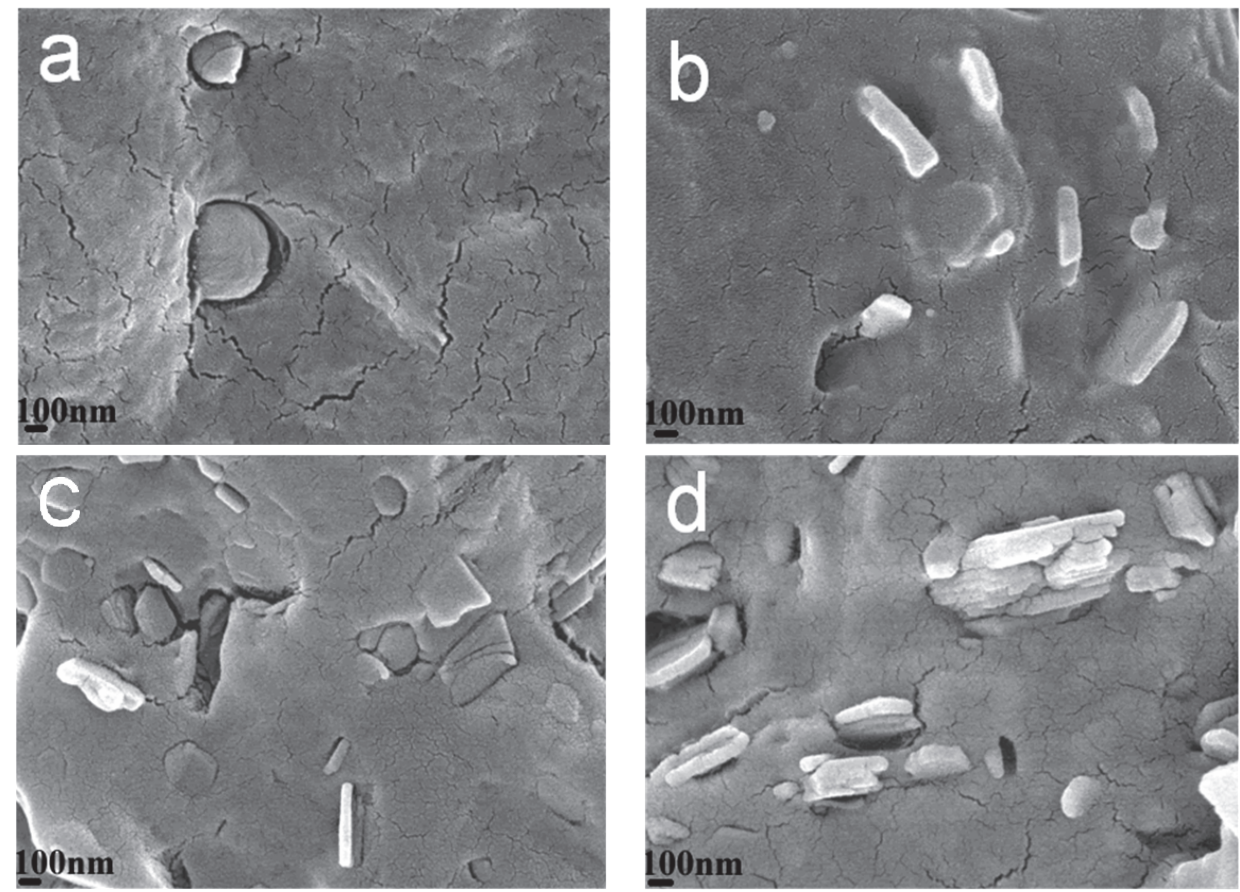

Figure 4: SEM images of PA6, PA6/MCA, and PA6/MCA- $\alpha$-ZrP composites: (a) PA6, (b) PA6/MCA, (c) PA6/MCA-10 $\alpha$-ZrP, and (d) PA6/MCA- $30 \alpha-Z r P$.

PA6 continued to decompose with heating and there was nothing left at $700^{\circ} \mathrm{C}$. As shown in Figure 6 and Table 1, PA6/MCA and PA6/MCA- $\alpha-Z$ rP had two stages of thermal degradation and the first temperature of rapid lost weight $\left(T_{\max 1}\right)$ appeared with the adding of MCA. And $T_{\max 1}$ was much lower than the thermal degradation of PA6, indicating that MCA can induce PA6 to catalytic decomposition. The decomposition process of PA6/MCA started at approximately $320^{\circ} \mathrm{C}$ and ended at $480^{\circ} \mathrm{C}$. And the remaining mass at $700^{\circ} \mathrm{C}$ was almost $0 \%$, which revealed the flame-retardant effect of 

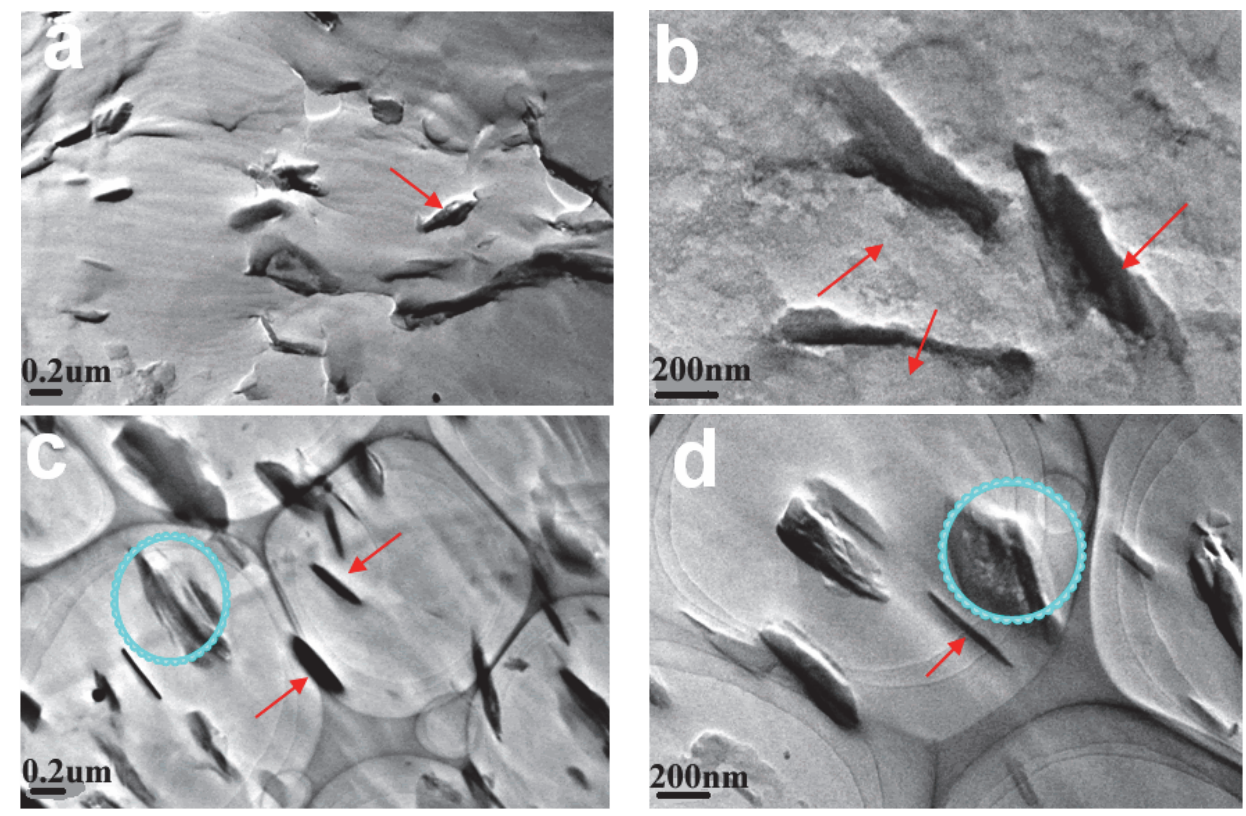

Figure 5: TEM images of PA6/MCA and PA6/MCA- $\alpha$-ZrP composites. ((a), (b)) PA6/MCA. ((c), (d)) PA6/MCA-30 $\alpha$-ZrP.

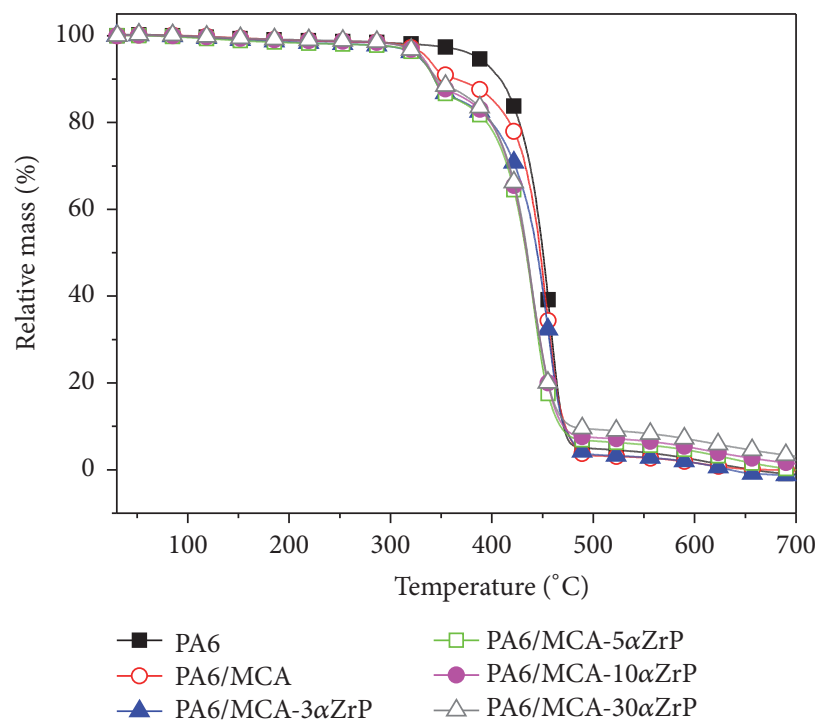

(a)

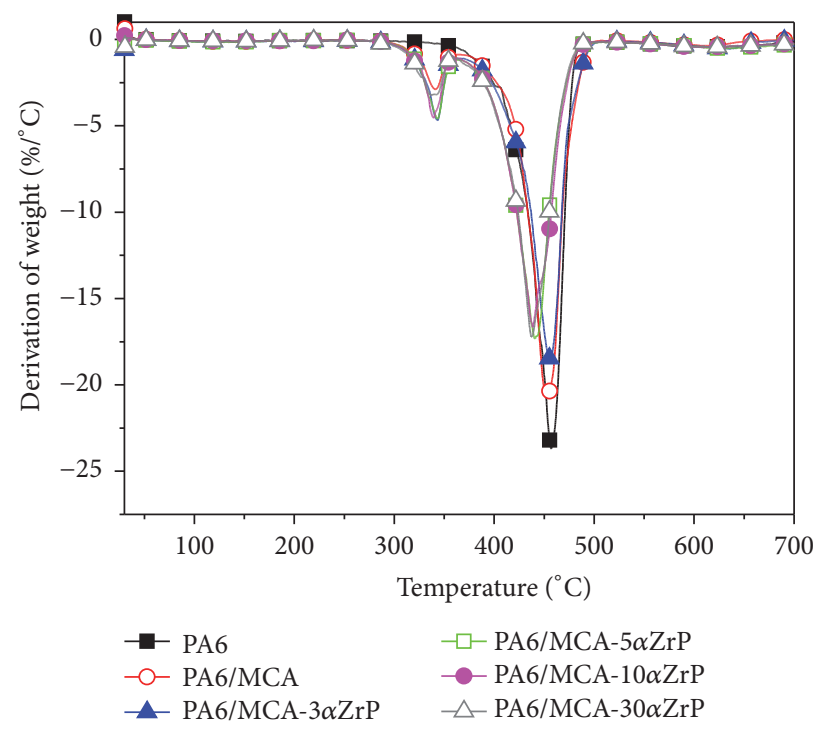

(b)

Figure 6: (a) TG and (b) DTG curves for pure PA6, PA6/MCA, and PA6/MCA- $\alpha$-ZrP composites.

MCA was in gaseous phase rather than in condensed phase $[26,27]$. As seen in Table 1, PA6/MCA and PA6/MCA- $\alpha$ $\mathrm{ZrP}$ composites increased $T_{i}$ compared to pure PA6. MCA may release the inert gases and dilute the concentration of combustible gases in high temperature; hence $T_{i}$ of the whole composites was postponed. As $\alpha$-ZrP was added to the PA6/MCA-3 $\alpha-\mathrm{ZrP}$ composites, $T_{\max 2}$ was slightly higher than that of PA6/MCA. It is postulated that $\alpha-\mathrm{ZrP}$ would enhance the thermal stability through forming a barrier layer and a compact carbon layer, which shows a relative high synergistic efficiency of MCA- $\alpha$-ZrP flame-retardant system. On the other hand, too much $\alpha$-ZrP may cause agglomeration and decrease $T_{\max 2}$. What is more, there were only PA6/MCA-10 $\alpha-\mathrm{ZrP}$ and PA6/MCA-30 $\alpha-\mathrm{ZrP}$ with char residues of 1.38 and $3.12 \%$ at $700^{\circ} \mathrm{C}$, respectively. Meanwhile other composites had nothing remained at $700^{\circ} \mathrm{C}$. There was no marked increase in char yield with a small quantity of $\alpha$-ZrP added to MCA- $\alpha$-ZrP. However, higher loading of $\alpha$ $\mathrm{ZrP}$ resulted in greater increases in char residues, about $126 \%$, which suggests that $\alpha$-ZrP plays a catalyzing carbonization role in MCA- $\alpha$-ZrP flame-retardant system.

To get sufficient information about the thermal stability and heat resistance of the above composites, the heat distortion temperature (HDT) of pure PA6 and the 
TABLE 2: DSC data of the pure PA6 and its composites.

\begin{tabular}{|c|c|c|c|c|c|c|c|}
\hline Samples ID & Composites & $T_{\gamma}\left({ }^{\circ} \mathrm{C}\right)$ & $T_{\alpha}\left({ }^{\circ} \mathrm{C}\right)$ & $f_{\gamma}(\%)$ & $f_{\alpha}(\%)$ & $\Delta H c(\mathrm{~J} / \mathrm{g})$ & $X_{c}(\%)$ \\
\hline 1 & PA6 & 210 & 219 & 22 & 78 & 62 & 33 \\
\hline 2 & PA6/MCA & 212 & 219 & 26 & 74 & 49 & 30 \\
\hline 3 & PA6/MCA-3 $\alpha-\mathrm{ZrP}$ & 214 & 220 & 43 & 57 & 51 & 31 \\
\hline 4 & PA6/MCA- $5 \alpha-\mathrm{ZrP}$ & 214 & 220 & 43 & 57 & 42 & 25 \\
\hline 5 & $\mathrm{PA} 6 / \mathrm{MCA}-10 \alpha-\mathrm{ZrP}$ & 213 & 219 & 34 & 66 & 44 & 26 \\
\hline 6 & PA6/MCA-30 $\alpha-Z r P$ & 212 & 220 & 37 & 63 & 62 & 38 \\
\hline
\end{tabular}

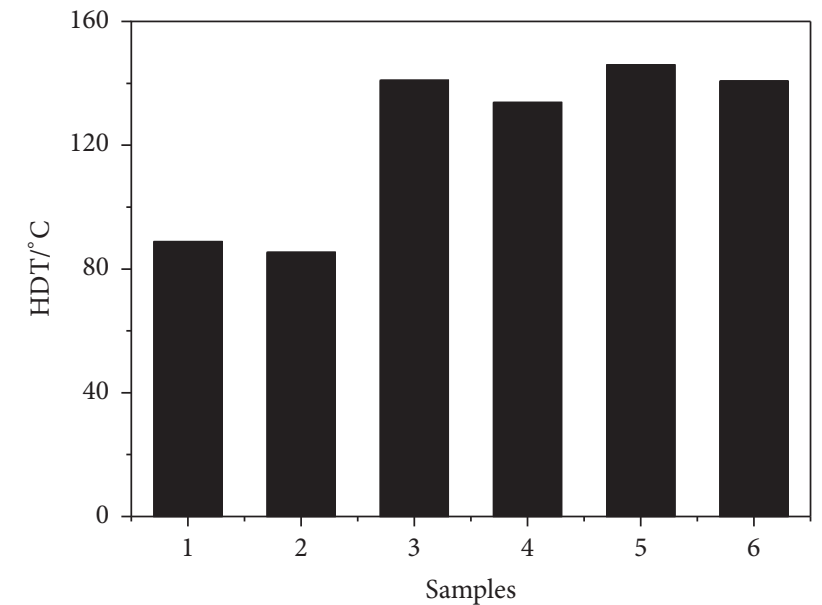

Figure 7: HDT of PA6, PA6/MCA, and PA6/MCA- $\alpha-Z r P$ composites.

flame-retardant PA6 systems with various amounts of $\alpha$ $\mathrm{ZrP}$ modified MCA were investigated. Figure 7 shows the HDT of PA6, PA6/MCA, and PA6/MCA- $\alpha$-ZrP composites. According to the literature, incorporation of nanofiller can increase the HDT of PA6 drastically $[28,29]$, and there is no exception of $\alpha-\mathrm{ZrP}$. In our study, it was found that the HDT of PA6/MCA- $\alpha$-ZrP composites increased sharply from $88.8^{\circ} \mathrm{C}$ to $140.9^{\circ} \mathrm{C}, 133.8^{\circ} \mathrm{C}, 145.9^{\circ} \mathrm{C}$, and $140.6^{\circ} \mathrm{C}$ of PA6/3 $\alpha$-ZrP-MCA, PA6/5 $\alpha$-ZrP-MCA, PA6/10 $\alpha$-ZrP-MCA, and PA6/30 $\alpha$-ZrP-MCA, respectively. The marked increase in HDT may be due to the strong hydrogen bonds between the matrix and the phosphate surface and the more perfect crystals formed in PA6/MCA- $\alpha-Z r P$ composites [3], so in the following discussion we will get involved in crystallinity and mechanical property. It is also particularly interesting to note that the HDT values of PA6/MCA- $\alpha-\mathrm{ZrP}$ composites with various addition of $\alpha-\mathrm{ZrP}$ only have small changes. The main reason for this phenomenon is the saturated mechanical stability and the crystallization degree of composites.

3.4. Thermal Transitions and Crystallinity. The DSC thermograms of PA6 contains a double melting peak, with the peak located at $212^{\circ} \mathrm{C}$ corresponding to $\gamma$-form crystals of PA6, whereas the other peak centered at $220^{\circ} \mathrm{C}$ can be attributed to $\alpha$-form crystals of PA6 [30, 31]. As shown in Figure $8(\mathrm{a})$, there are no obvious differences observed on the curve of each composite, and while magnifying this picture, a double-peak is visible in Figure 8(b) (pure PA6). Figure 8(b) shows a measurement to calculate $X_{c}$ and $f_{\gamma}$ through defining the baseline used for the peaks' integration $[32,33]$. The crystallinity was calculated according to the following equation:

$$
X c(\%)=\frac{\Delta H c}{[\Delta H o(1-\phi)]},
$$

where $\phi$ is the weight fraction of MCA and MCA- $\alpha-\mathrm{ZrP}, \Delta H o$ is the enthalpy of melting of $100 \%$ crystalline PA6 taking a value of $190 \mathrm{~J} / \mathrm{g}[34,35]$.

The crystallinity values, $X_{c}$, obtained with different $\alpha$ $\mathrm{ZrP}$ contents are reported in Table 2. Moreover, the relative proportion of $\gamma$ phase and $f_{\gamma}$ values have been calculated by the ratio between the area of $\gamma$ melting peak and the total melting peak according to Figure 8(b). All the DSC results were presented in Table 2. The crystallization temperatures of $\gamma$ phase $\left(T_{\gamma}\right)$ and $\alpha$ phase $\left(T_{\alpha}\right)$ were about $212^{\circ} \mathrm{C}$ and $220^{\circ} \mathrm{C}$, respectively, which are consistent with the foregoing. It shows that the crystallization temperatures do not depend on the presence of filler. Two main conclusions can be drawn from Table 2, the crystallinity $X_{c}$ was increased eventually, indicating that the ability of PA6/MCA- $\alpha$-ZrP to crystallize was further improved when enough $\alpha$-ZrP was incorporated into the composites, leading to more perfect crystals formed, besides, both $\alpha$ and $\gamma$ phases coexist, and $\gamma$ phase seems to depend on the presence of nanofiller $\alpha-\mathrm{ZrP}$, which can be seen from $f_{\gamma}$ promoted from 22 to $43 \%$

A deeper analysis was performed by XRD. Figure 9 shows the XRD patterns of PA6, PA6/MCA, and PA6/MCA- $\alpha-\mathrm{ZrP}$ composites. Devaux et al. [36] reported that the peak located at $21.3^{\circ}$ was $\alpha$ phase and that at $24^{\circ}$ was $\gamma$ phase. In pure PA6, the peak primarily concentrated on $24^{\circ}$, indicating that pure PA6 have a preference for crystallizing in $\alpha$ phase. From Figure 9, we can see that nanofiller $\alpha$-ZrP added to the composites tend to form $\gamma$ phase, which is in accordance with the DSC results. What is more, the peaks of PA6/MCA- $\alpha$ $\mathrm{ZrP}$ located at $21.3^{\circ}$ and $24^{\circ}$ become more intensive than pure PA6. It suggests that nanofiller $\alpha$-ZrP tend to improve $X_{c}$ of the whole composites which is consistent with the DSC results, and this is the reason why the HDT of PA6/MCA- $\alpha$ $\mathrm{ZrP}$ increased sharply compared to that of pure PA6.

3.5. Combustion Properties of Flame Retarded PA6 Composites. UL-94 vertical burning tests were widely used to evaluate the flame-retardant properties of materials [37-39]. The effect of $\alpha-\mathrm{ZrP}$ on the flame retardancy of flame retarded 


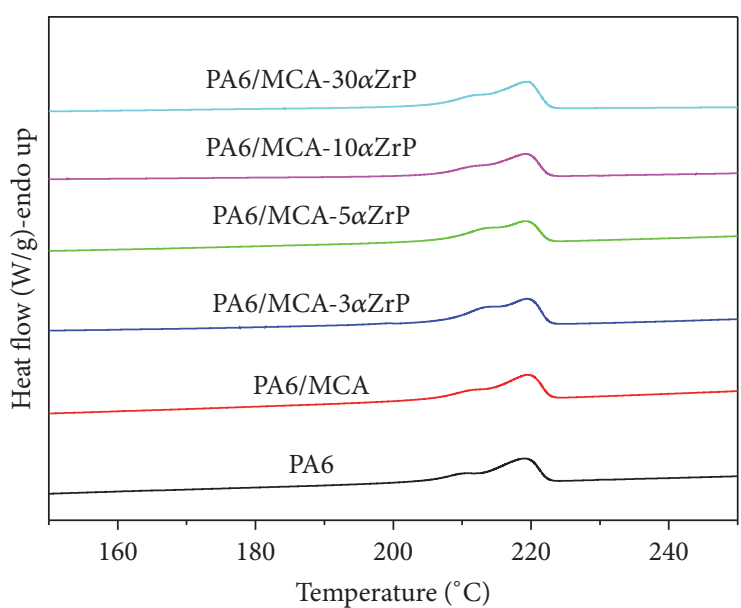

(a)

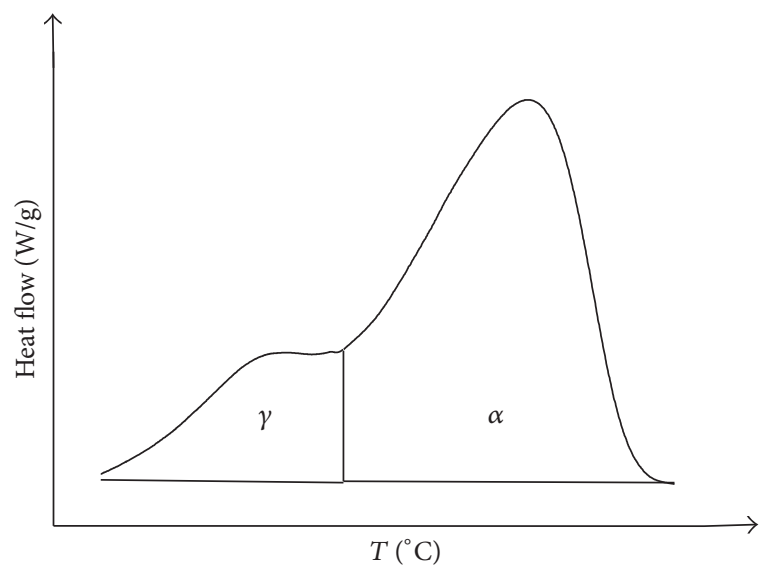

(b)

Figure 8: DSC curves of (a) PA6, PA6/MCA, and PA6/MCA- $\alpha-Z r P$ composites and (b) definition of base line used to calculate $X_{c}$ and $f_{\gamma}$.

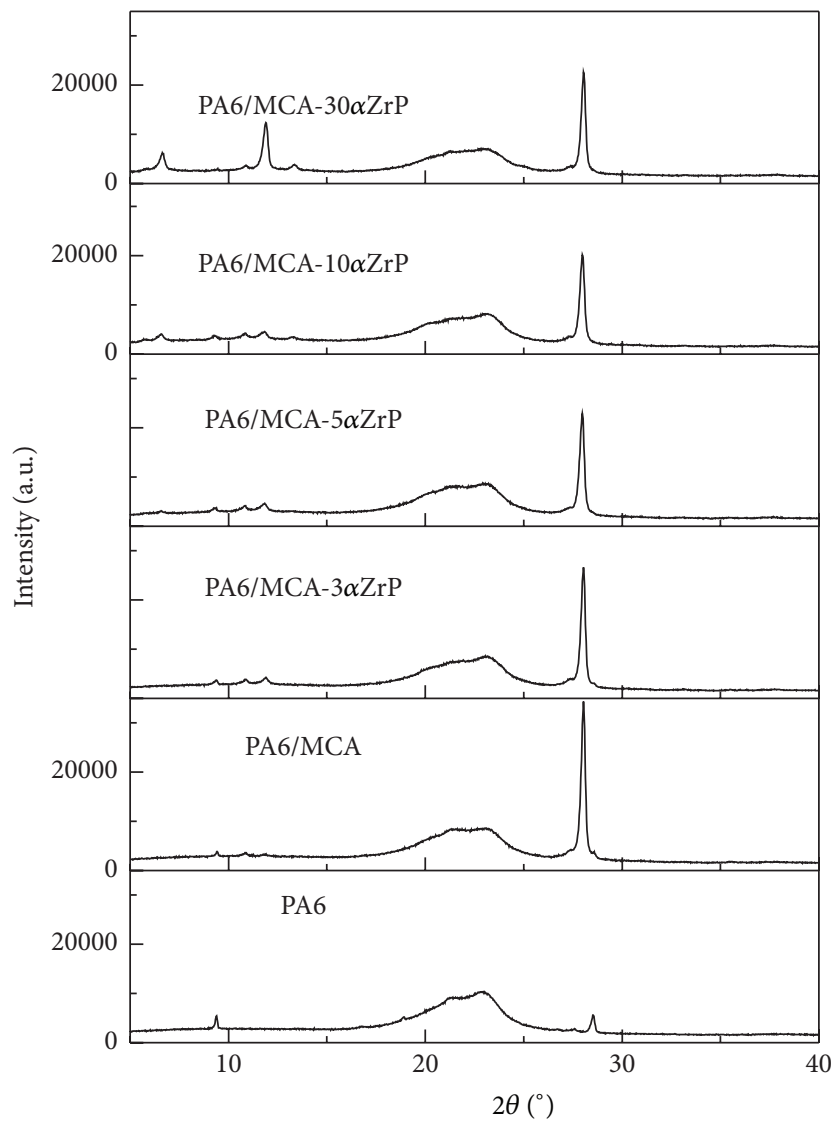

Figure 9: XRD patterns of PA6, PA6/MCA, and PA6/MCA- $\alpha-\mathrm{ZrP}$ composites.

PA6 composites is listed in Table 3. The total addition of the flame retardant in the test was kept at $12 \mathrm{wt} \%$. When MCA was added to PA6, the flame retardancy of PA6 reached UL94 rating. When $\alpha-\mathrm{ZrP}$ was added to PA6/MCA composites, the UL-94 rating increased from V-2 to V-0 and the dripping
TABLE 3: UL-94 test of the flame retardant PA6.

\begin{tabular}{lcccc}
\hline \multirow{2}{*}{ Samples } & \multicolumn{4}{c}{ UL-94 } \\
& Dripping & \multicolumn{2}{c}{ Burning times/s } & Rank \\
& & T1 & T2 & \\
\hline PA6 & Yes & - & - & NR \\
PA6/MCA & Yes & 15 & 10 & V-2 \\
PA6/MCA-3 $\alpha$-ZrP & Yes & 15 & 10 & V-2 \\
PA6/MCA-5 $\alpha-Z r P$ & No & 10 & 12 & V-0 \\
PA6/MCA-10 $\alpha$-ZrP & No & 10 & 10 & V-0 \\
PA6/MCA-30 $\alpha-Z r P$ & No & 10 & 10 & V-0 \\
\hline
\end{tabular}

phenomenon was improved. The results clearly clarify a synergistic effect between MCA and $\alpha$-ZrP as well as optimal $\alpha$-ZrP contents in this system for the best flame retardancy of PA6, which is in accordance with the TG results.

CCT is a useful tool for the evaluation of flameretardant materials and it can be used to simulate real fire conditions [40-42]. The heat release rate curves of PA6/MCA, PA6/MCA-10 $\alpha-\mathrm{ZrP}$, and PA6/MCA-30 $\alpha-\mathrm{ZrP}$ composites were presented in Figure 10(a). It can be seen that peak heat release rate (PHRR) of PA6/MCA was $928 \mathrm{~kW} / \mathrm{m}^{2}$, while the PHRR of PA6/MCA- $10 \alpha-\mathrm{ZrP}$ and PA6/MCA$30 \alpha$-ZrP composites were 774 and $928 \mathrm{~kW} / \mathrm{m}^{2}$, respectively. PA6/MCA and PA6/MCA-30 $\alpha-Z r P$ had the same PHRR values. It is supposed that too much stacked $\alpha-\mathrm{ZrP}$ in matrix may decrease its flame retardancy. The detailed data is shown in Table 4.

There are also considerable differences in the THR curves presented in Figure 10(b). THR of PA6/MCA was $83 \mathrm{MJ} / \mathrm{m}^{2}$, and PA6/MCA-10 $\alpha-\mathrm{ZrP}$ and PA6/MCA-30 $\alpha-\mathrm{ZrP}$ released 59 and $60 \mathrm{MJ} / \mathrm{m}^{2}$, respectively. It shows that PA6/MCA composites with $\alpha-\mathrm{ZrP}$ reduce the total amount of fuel available for combustion. Both HRR and THR curves reveal that PA6/MCA-10 $\alpha-\mathrm{ZrP}$ possess the best flame retardancy. 


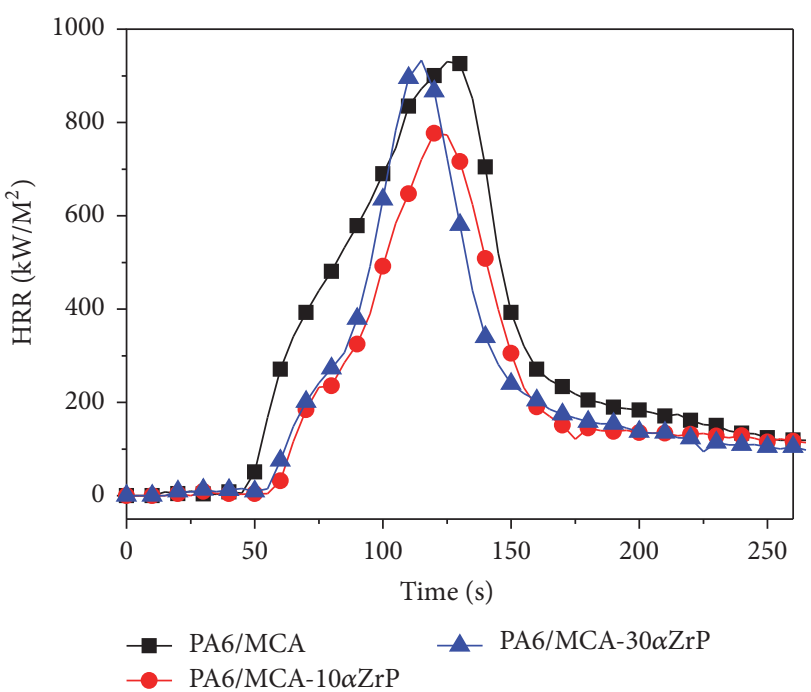

(a)

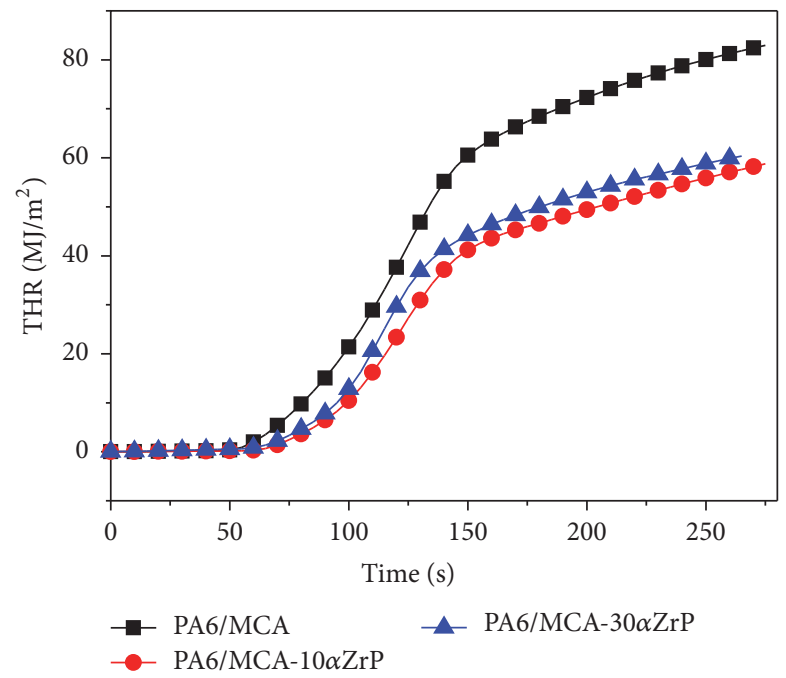

(b)

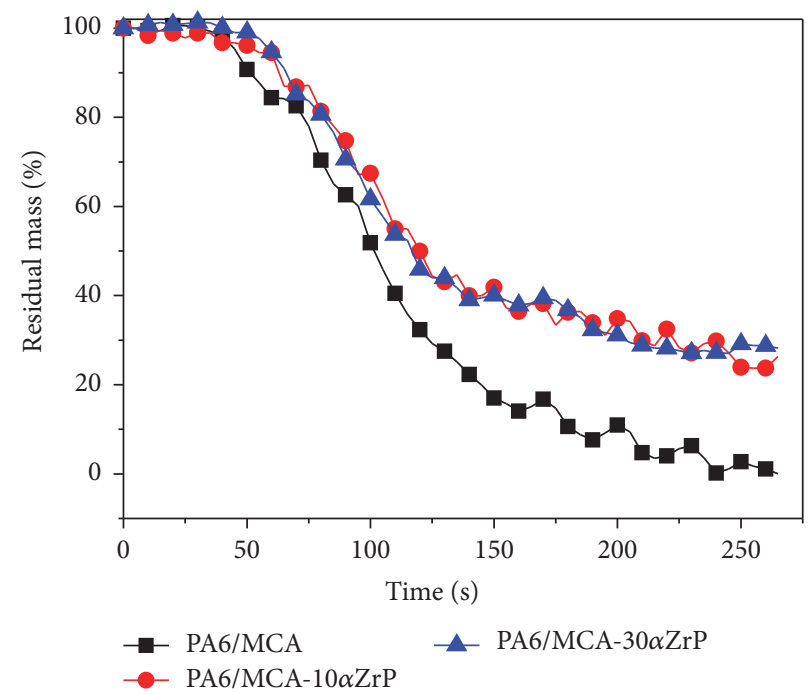

(c)

Figure 10: (a) Heat release rate (HRR), (b) total heat release (THR), and (c) residual mass loss for PA6/MCA, PA6/MCA-10 $\alpha$-ZrP, and PA6/MCA-30 $\alpha$-ZrP composites.

TABLE 4: Combustion parameters obtained from cone calorimeter.

\begin{tabular}{lcccccc}
\hline Samples & TTI $(\mathrm{s})$ & PHRR $\left(\mathrm{kW} / \mathrm{m}^{2}\right)$ & $\mathrm{T}_{\text {PHR }}(\mathrm{s})$ & FIGRA $(\mathrm{W} / \mathrm{s})$ & THR MJ/m & Residual mass $(\%)$ \\
\hline PA6/MCA & 49 & 928 & 129 & 7.2 & 83 & 0.4 \\
PA6/MCA-10 $\alpha$-ZrP & 55 & 774 & 124 & 6.2 & 59 & 26.4 \\
PA6/MCA-30 $\alpha$-ZrP & 58 & 928 & 116 & 8.0 & 60 & 28.2 \\
\hline
\end{tabular}

TTI: time to ignition; $\mathrm{T}_{\mathrm{PHR}}$ : time to peak heat release rate; FIGRA: fire growth rate; THR: total heat release.

It means that there is the best synergistic effect between $10 \mathrm{wt} \% \alpha$-ZrP and MCA in this composite.

Figure 10(c) shows residual mass curves of PA6/MCA, PA6/MCA-10 $\alpha-\mathrm{ZrP}$, and PA6/MCA-30 $\alpha-\mathrm{ZrP}$ composites. It can be seen that PA6/MCA with $\alpha$-ZrP present a considerably lower mass loss and a condensed phase mechanism, which further indicates that the $\alpha$-ZrP can catalyze carbonization and prevent the mass and heat transfer.

To further study the flame-retardant mechanism of $\alpha$ $\mathrm{ZrP}$ on PA6/MCA- $\alpha$-ZrP system, the morphology of the residual chars of the samples after UL-94 test was observed via SEM. From Figure 11(a), a lot of gas holes can be seen 


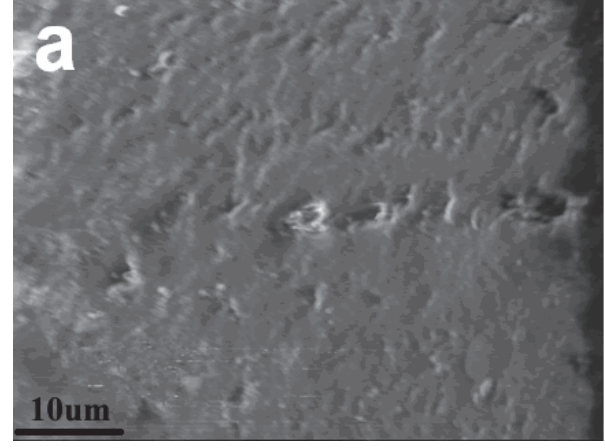

(a)

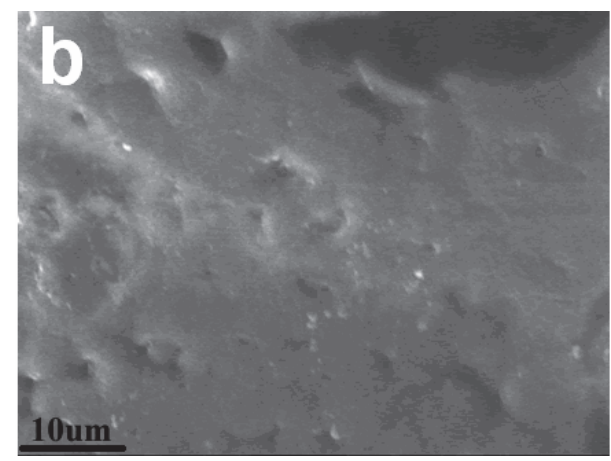

(b)

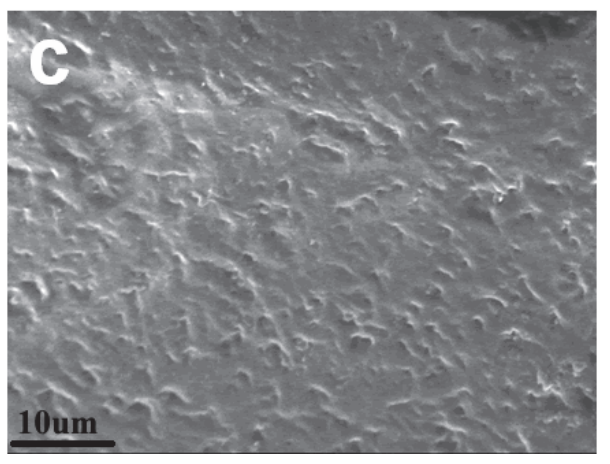

(c)

Figure 11: SEM images of the charred residue after UL-94 test: (a) PA6/MCA, (b) PA6/MCA-10 $\alpha$-ZrP, and (c) PA6/MCA-30 $\alpha$-ZrP.

on the char residue surface of PA6/MCA due to the gas phase flame-retardant mechanism of MCA. This insufficient char formation and less condensed char cannot effectively prevent the underlying polymer composites from degradation during combustion which may be the primary reason for poor flame retardancy [14]. However, the char surface of PA6/MCA with $\alpha$-ZrP (Figure 11(c)) is compact and tight, which can serve as a barrier to prevent the transfer of heat and mass, thus effectively protecting the underlying PA6. It is supposed that $\alpha-\mathrm{ZrP}$ can lead to the formation of ceramic-like material with a homogeneous surface, which will protect the material throughout combustion, and also a mechanical reinforcement of the charred layer, reducing char opening $[17,43]$. The possible mechanism is that not only may layered $\alpha$-ZrP form a barrier, which inhibits mass transfer and heat exchange to shield the underlying polymer from the fire source, but also $\alpha$-ZrP may thermally loose $\mathrm{H}^{+}$proton acid sites on the degraded $\alpha$-ZrP layers, which will attack molecular chains of PA6 to form cationic active sites, and thus catalyze carbonization at the surface of polymer composites [44]. What is more, MCA and $\alpha-\mathrm{ZrP}$ had synergistic effect to protect PA6 by comparison of the SEM images of PA6/MCA and PA6/MCA- $\alpha-\mathrm{ZrP}$.

3.6. Mechanical Property. The impact strength, tensile strength, and elongation ratio of PA6, PA6/MCA, and PA6/MCA- $\alpha$-ZrP are shown in Figure 12. As we all know, there is a strong interaction between matrix and phosphate layers via formation of hydrogen bonds hence improving the mechanical properties of composites [3]. However, from the picture we can see that the impact strength and tensile strength have no obvious changes with $\alpha$-ZrP added to PA6/MCA, while the elongation ratio decreases drastically from 9.5 to $2.2 \%$. The main reason for this phenomenon can be attributed to the uneven dispersion of MCA and stacked fillers in composites. The uneven dispersion of MCA and stacked fillers in composites were the stress concentration points and would seriously damage the impact strength and tensile property of composites. The influences of this stress concentration points were offset by the strong interaction and thus shown as Figure 12.

\section{Conclusion}

MCA- $\alpha$-ZrP were synthesized by self-assembly of ME and CA on the surface of $\alpha$-ZrP powders. $T_{i}$ of PA6/MCA and PA6/MCA- $\alpha-Z r P$ composites were increased compared to that of pure PA6. The HDT values of PA6/MCA- $\alpha-\mathrm{ZrP}$ with different $\alpha$-ZrP contents were much higher than that of pure PA6 and PA6/MCA composites. UL-94 results showed that the introduction of MCA enhanced flame retardancy to $\mathrm{V}$ 2 rating and $\alpha$-ZrP modified MCA to $\mathrm{V}-0$ rating. The cone calorimeter results showed PA6/10 $\alpha$-ZrP-MCA composites with lower HRR, lower THR, and higher amounts of char residues after combustion. The incorporation of enough $\alpha$ $\mathrm{ZrP}$ (30 wt $\%$ MCA) caused the increased crystallinity of PA6 and tended to form $\gamma$ phase. SEM and TEM demonstrated that the dispersion of MCA and $\alpha$-ZrP fillers was not as 


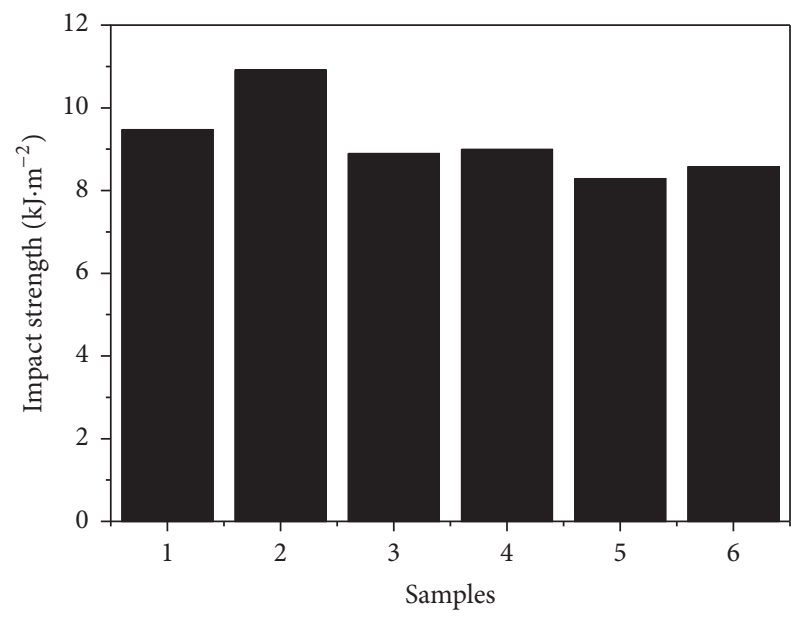

(a)

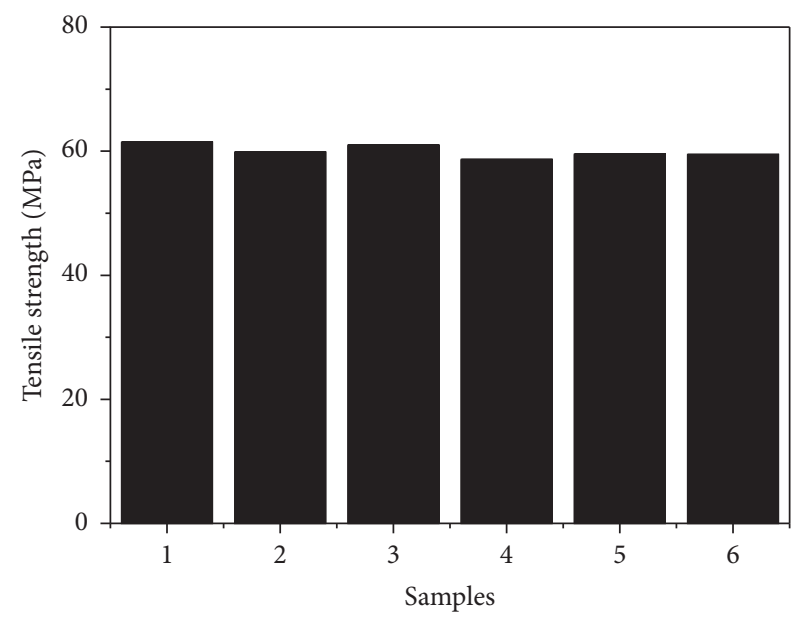

(b)

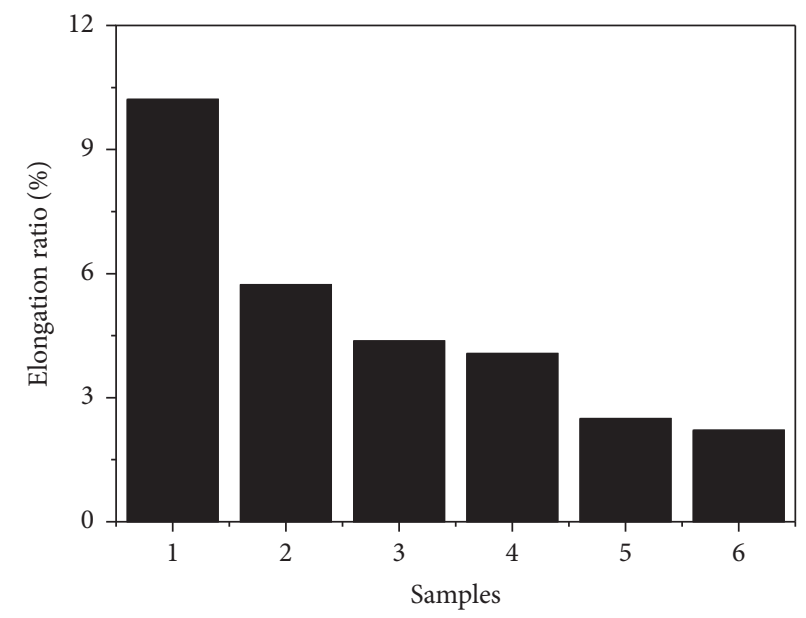

(c)

FIGURE 12: (a) Impact strength, (b) tensile strength, and (c) elongation ratio of PA6, PA6/MCA, and PA6/MCA- $\alpha$-ZrP composites.

good as expected, while it was not at the sacrifice of PA6's mechanical properties because of its strong hydrogen bonds between $\alpha$-ZrP and PA6. These results indicated that $\alpha-\mathrm{ZrP}$ and MCA had a significant synergistic effect to improve PA6's flame retardancy and crystallinity and keep the excellent mechanical properties at the same time.

\section{Competing Interests}

The authors declare that there is no conflict of interests regarding the publication of this paper.

\section{References}

[1] S. V. Levchik and E. D. Weil, "Combustion and fire retardancy of aliphatic nylons," Polymer International, vol. 49, no. 10, pp. 1033-1073, 2000.

[2] B. N. Jang and C. A. Wilkie, "The effect of clay on the thermal degradation of polyamide 6 in polyamide 6/clay nanocomposites," Polymer, vol. 46, no. 10, pp. 3264-3274, 2005.

[3] G.-M. Kim, S. Goerlitz, and G. H. Michler, "Deformation mechanism of nylon 6/layered silicate nanocomposites: role of the layered silicate," Journal of Applied Polymer Science, vol. 105, no. 1, pp. 38-48, 2007.

[4] J. Jordan, K. I. Jacob, R. Tannenbaum, M. A. Sharaf, and I. Jasiuk, "Experimental trends in polymer nanocomposites-a review," Materials Science and Engineering A, vol. 393, no. 1-2, pp. 1-11, 2005.

[5] H. Zhang, X. Lu, and Y. Zhang, "Synergistic effects of rare earth oxides on intumescent flame retardancy of Nylon 1010/ethylene-vinyl-acetate rubber thermoplastic elastomers," Journal of Polymer Research, vol. 22, article 21, 2015.

[6] S. Sinha Ray and M. Okamoto, "Polymer/layered silicate nanocomposites: a review from preparation to processing," Progress in Polymer Science, vol. 28, no. 11, pp. 1539-1641, 2003.

[7] S. Pack, T. Kashiwagi, C. Cao, C. S. Korach, M. Lewin, and M. H. Rafailovich, "Role of surface interactions in the synergizing polymer/clay flame retardant properties," Macromolecules, vol. 43, no. 12, pp. 5338-5351, 2010.

[8] Z. Zheng, H. Sun, W. Li et al., "Co-microencapsulation of ammonium polyphosphate and aluminum hydroxide in halogen-free and intumescent flame retarding polypropylene," Polymer Composites, vol. 35, no. 4, pp. 715-729, 2014.

[9] H. Sue, K. T. Gam, N. Bestaoui, N. Spurr, and A. Clearfield, "Epoxy nanocomposites based on the synthetic $\alpha$-zirconium 
phosphate layer structure," Chemistry of Materials, vol. 16, no. 2, pp. 242-249, 2004.

[10] L. Sun, W. J. Boo, R. L. Browning, H.-J. Sue, and A. Clearfield, "Effect of crystallinity on the intercalation of monoamine in $\alpha$ zirconium phosphate layer structure," Chemistry of Materials, vol. 17, no. 23, pp. 5606-5609, 2005.

[11] L. Sun, W. J. Boo, D. Sun, A. Clearfield, and H.-J. Sue, "Preparation of exfoliated epoxy $/ \alpha$-zirconium phosphate nanocomposites containing high aspect ratio nanoplatelets," Chemistry of Materials, vol. 19, no. 7, pp. 1749-1754, 2007.

[12] L. F. Xu, C. H. Lei, R. J. Xu, X. Q. Zhang, and F. Zhang, "Hybridization of $\alpha$-zirconium phosphate with hexachlorocyclotriphosphazene and its application in the flame retardant poly(vinyl alcohol) composites," Polymer Degradation and Stability, vol. 133, pp. 378-388, 2016.

[13] M. Tang, T. Yang, and Y. Zhang, "A brief review on $\alpha$-zirconium phosphate intercalation compounds and nano-composites," Science China Technological Sciences, vol. 59, no. 3, pp. 436-441, 2016.

[14] C. Zhao, P. Li, D. He, Y. Li, F. Lei, and H. Sue, "Flame retardation behavior of polybenzoxazine $/ \alpha-\mathrm{ZrP}$ nanocomposites," $R S C$ Advances, vol. 6, no. 77, pp. 73485-73495, 2016.

[15] L. Xu, C. Lei, R. Xu, X. Zhang, and F. Zhang, "Functionalization of $\alpha$-zirconium phosphate by polyphosphazene and its effect on the flame retardance of an intumescent flame retardant polypropylene system," RSC $A d v$., vol. 6, no. 81, pp. 7754577552, 2016.

[16] D.-Y. Wang, X.-Q. Liu, J.-S. Wang, Y.-Z. Wang, A. A. Stec, and T. R. Hull, "Preparation and characterisation of a novel fire retardant PET/ $\alpha$-zirconium phosphate nanocomposite," Polymer Degradation and Stability, vol. 94, no. 4, pp. 544-549, 2009.

[17] D.-D. Yang, Y. Hu, H.-P. Xu, and L.-P. Zhu, "Catalyzing carbonization of organophilic alpha-zirconium phosphate/ acrylonitrile-butadiene-styrene copolymer nanocomposites," Journal of Applied Polymer Science, vol. 130, no. 5, pp. 30383042, 2013.

[18] X.-Q. Liu, D.-Y. Wang, X.-L. Wang, L. Chen, and Y.-Z. Wang, "Synthesis of organo-modified $\alpha$-zirconium phosphate and its effect on the flame retardancy of IFR poly(lactic acid) systems," Polymer Degradation and Stability, vol. 96, no. 5, pp. 771-777, 2011.

[19] D. Yang, Y. Hu, H. Li et al., "Flammability and carbonization of high-impact polystyrene $/ \alpha$-zirconium phosphate nanocomposites," Iranian Polymer Journal, vol. 24, no. 12, pp. 1069-1075, 2015.

[20] D. Yang, Y. Hu, H. Li, L. Song, H. Xu, and B. Li, "Synergistic flame retardant effect of $\alpha$-zirconium phosphate in lowdensity polyethylene/ethylene-vinyl acetate/aluminum hydroxide hybrids," Journal of Thermal Analysis and Calorimetry, vol. 119, no. 1, pp. 619-624, 2015.

[21] J. Alongi and A. Frache, "Flame retardancy properties of $\alpha$ zirconium phosphate based composites," Polymer Degradation and Stability, vol. 95, no. 9, pp. 1928-1933, 2010.

[22] Y. Liu and Q. Wang, "Preparation of microencapsulated red phosphorus through melamine cyanurate self-assembly and its performance in flame retardant polyamide 6," Polymer Engineering \& Science, vol. 46, no. 11, pp. 1548-1553, 2006.

[23] Y. Liu and Q. Wang, "The investigation on the flame retardancy mechanism of nitrogen flame retardant melamine cyanurate in polyamide 6," Journal of Polymer Research, vol. 16, no. 5, pp. 583589, 2009.
[24] K. D. Li, J. Y. Xu, and J. Liu, "Preparation of MCA-MMT and its effects on flame retardant properties of glass fiber reinforced polypropylene composites," Acta Materiae Compositae Sinica, vol. 32, no. 3, pp. 712-720, 2015.

[25] H. Ge, G. Tang, W.-Z. Hu et al., "Aluminum hypophosphite microencapsulated to improve its safety and application to flame retardant polyamide 6," Journal of Hazardous Materials, vol. 294, pp. 186-194, 2015.

[26] P. Gijsman, R. Steenbakkers, C. Fürst, and J. Kersjes, "Differences in the flame retardant mechanism of melamine cyanurate in polyamide 6 and polyamide 66," Polymer Degradation and Stability, vol. 78, no. 2, pp. 219-224, 2002.

[27] C. Isbasar and J. Hacaloglu, "Investigation of thermal degradation characteristics of polyamide- 6 containing melamine or melamine cyanurate via direct pyrolysis mass spectrometry," Journal of Analytical and Applied Pyrolysis, vol. 98, pp. 221-230, 2012.

[28] P.-C. Ma, N. A. Siddiqui, G. Marom, and J.-K. Kim, "Dispersion and functionalization of carbon nanotubes for polymer-based nanocomposites: a review," Composites Part A, vol. 41, no. 10, pp. 1345-1367, 2010.

[29] Z. Shen, S. Bateman, D. Y. Wu, P. McMahon, M. Dell'Olio, and J. Gotama, "The effects of carbon nanotubes on mechanical and thermal properties of woven glass fibre reinforced polyamide6 nanocomposites," Composites Science and Technology, vol. 69, no. 2, pp. 239-244, 2009.

[30] T.-M. Wu, E.-C. Chen, and C.-S. Liao, "Polymorphic behavior of nylon 6/saponite and nylon 6/montmorillonite nanocomposites," Polymer Engineering and Science, vol. 42, no. 6, pp. 11411150, 2002.

[31] P. Kiliaris, C. D. Papaspyrides, R. Xalter, and R. Pfaendner, "Study on the properties of polyamide 6 blended with melamine polyphosphate and layered silicates," Polymer Degradation and Stability, vol. 97, no. 7, pp. 1215-1222, 2012.

[32] L. Olivier, M. Sabard, R. Fulchiron, E. Espuche, L. David, and A. Guiu, "Influence of $\alpha$-ZrP fillers and process conditions on the morphology and the gas barrier properties of filled polyamide 6 films," Journal of Polymer Science, Part B: Polymer Physics, vol. 46, no. 16, pp. 1734-1746, 2008.

[33] L. Li, Z. Wu, S. Jiang et al., "Effect of halloysite nanotubes on thermal and flame retardant properties of polyamide 6/melamine cyanurate composites," Polymer Composites, vol. 36, no. 5, pp. 892-896, 2015.

[34] D. M. Lincoln, R. A. Vaia, Z.-G. Wang, B. S. Hsiao, and R. Krishnamoorti, "Temperature dependence of polymer crystalline morphology in nylon 6/montmorillonite nanocomposites," Polymer, vol. 42, no. 25, pp. 9975-9985, 2001.

[35] M. Inoue, "Studies on crystallization of high polymers by differential thermal analysis," Journal of Polymer Science Part A: General Papers, vol. 1, no. 8, pp. 2697-2709, 2007.

[36] E. Devaux, S. Bourbigot, and A. El Achari, "Crystallization behavior of PA-6 clay nanocomposite hybrid," Journal of Applied Polymer Science, vol. 86, no. 10, pp. 2416-2423, 2002.

[37] Y. Chen, J. Zhan, P. Zhang et al., "Preparation of intumescent flame retardant poly(butylene succinate) using fumed silica as synergistic agent," Industrial and Engineering Chemistry Research, vol. 49, no. 17, pp. 8200-8208, 2010.

[38] P. Jamshidi, D. Ghanbari, and M. Salavati-Niasari, "Sonochemical synthesis of $\mathrm{La}(\mathrm{OH}) 3$ nanoparticle and its influence on the flame retardancy of cellulose acetate nanocomposite," Journal of Industrial and Engineering Chemistry, vol. 20, no. 5, pp. 35073512, 2014. 
[39] A. Subasinghe and D. Bhattacharyya, "Performance of different intumescent ammonium polyphosphate flame retardants in $\mathrm{PP} /$ kenaf fibre composites," Composites Part A: Applied Science and Manufacturing, vol. 65, pp. 91-99, 2014.

[40] X. Hu, Y. Li, and Y. Wang, "Synergistic effect of the charring agent on the thermal and flame retardant properties of polyethylene," Macromolecular Materials and Engineering, vol. 289, no. 2, pp. 208-212, 2004.

[41] Q. Ren, C. Wan, Y. Zhang, and J. Li, "An investigation into synergistic effects of rare earth oxides on intumescent flame retardancy of polypropylene/poly (octylene-co-ethylene) blends," Polymers for Advanced Technologies, vol. 22, no. 10, pp. 1414-1421, 2011.

[42] S. Nie, Y. Hu, L. Song, Q. He, D. Yang, and H. Chen, "Synergistic effect between a char forming agent (CFA) and microencapsulated ammonium polyphosphate on the thermal and flame retardant properties of polypropylene," Polymers for Advanced Technologies, vol. 19, no. 8, pp. 1077-1083, 2008.

[43] D. Wang, Q. Zhang, K. Zhou, W. Yang, Y. Hu, and X. Gong, “The influence of manganese-cobalt oxide/graphene on reducing fire hazards of poly(butylene terephthalate)," Journal of Hazardous Materials, vol. 278, pp. 391-400, 2014.

[44] D. Yang, Y. Hu, L. Song, S. Nie, S. He, and Y. Cai, "Catalyzing carbonization function of $\alpha$-ZrP based intumescent fire retardant polypropylene nanocomposites," Polymer Degradation and Stability, vol. 93, no. 11, pp. 2014-2018, 2008. 

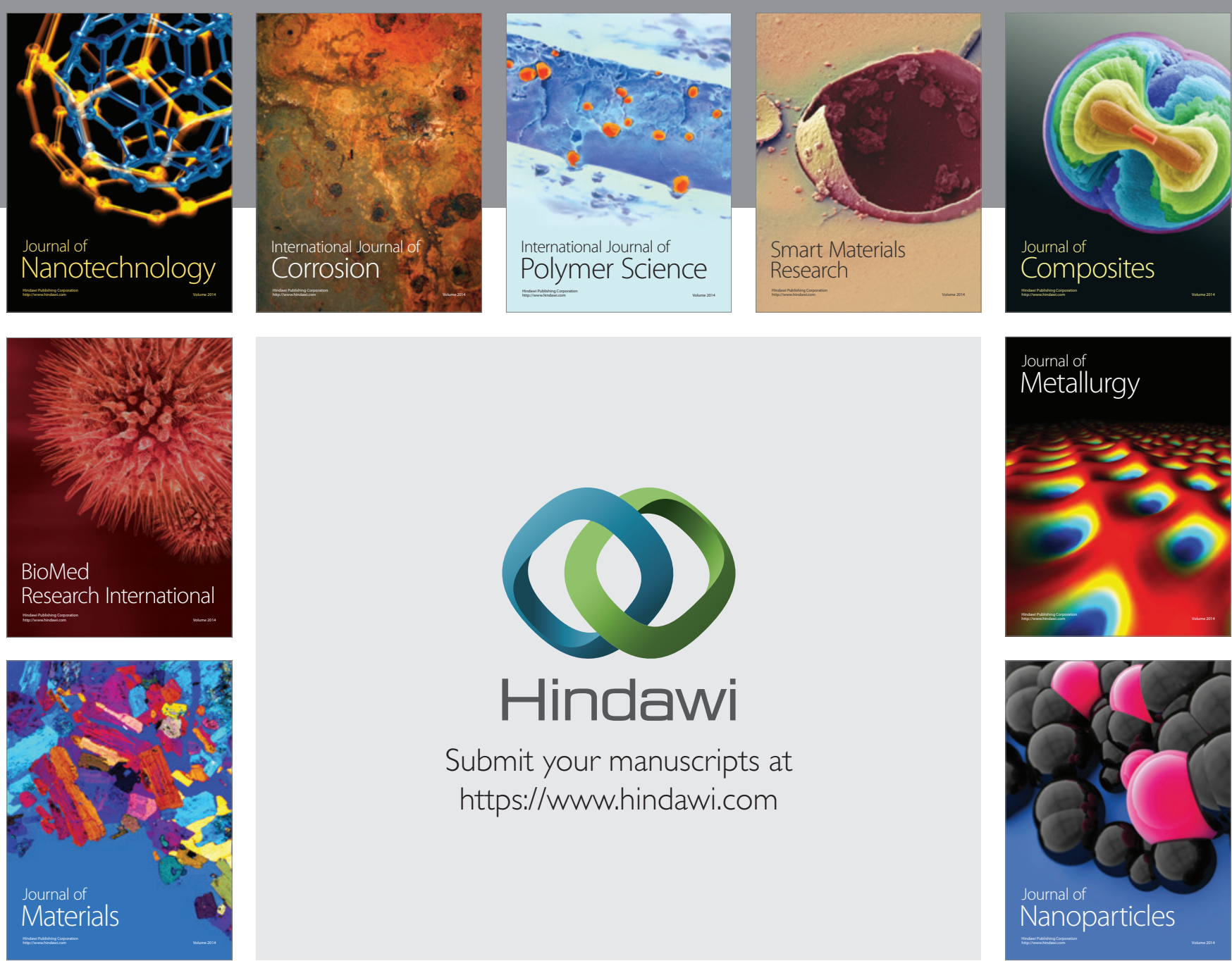

\section{Hindawi}

Submit your manuscripts at

https://www.hindawi.com

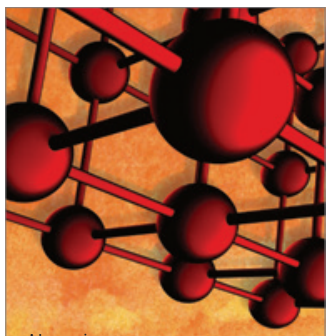

Materials Science and Engineering
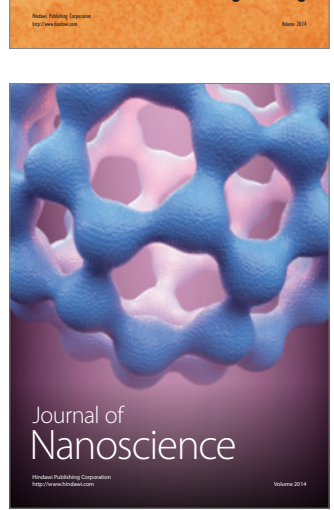
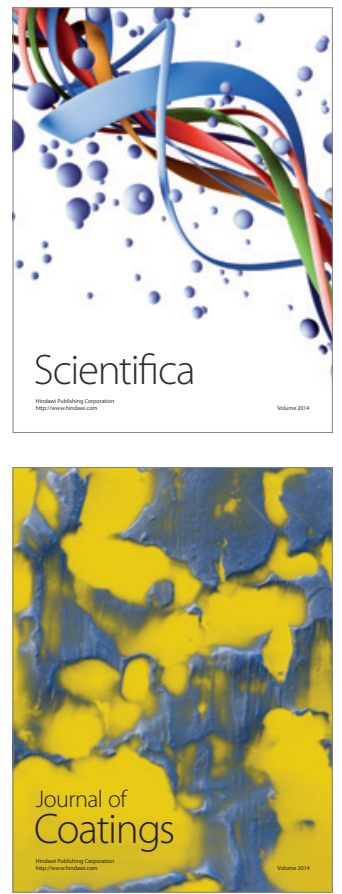
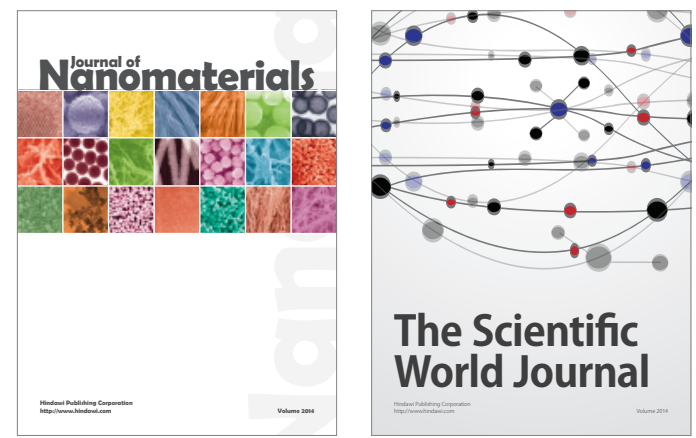

The Scientific World Journal
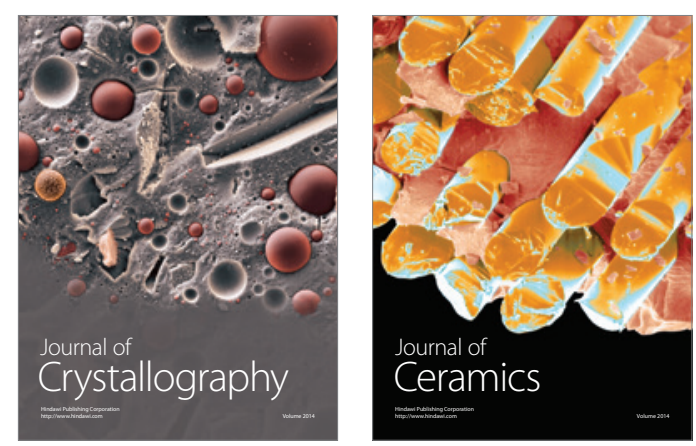
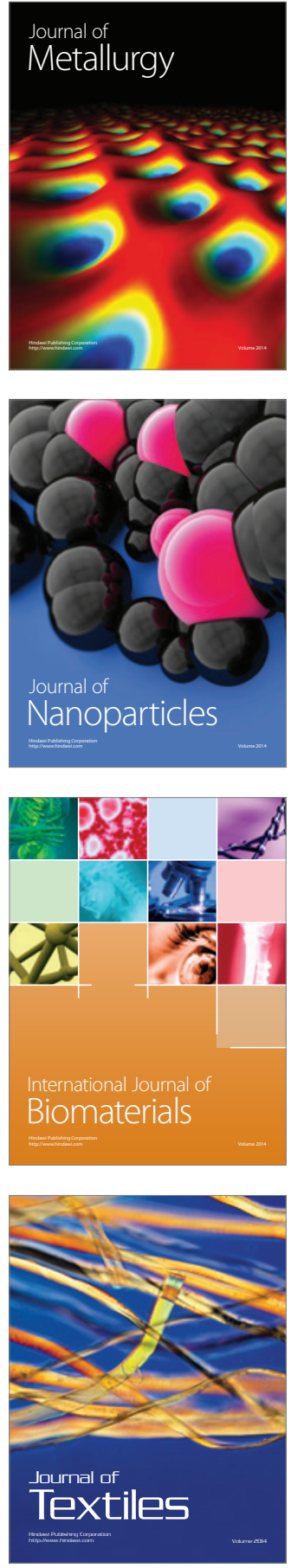